\title{
SCIENTIFIC WRITING AND PUBLISHING: ON THE SKILLS NEEDED TO WRITE AND SUBMIT SCIENTIFIC MANUSCRIPTS
}

\author{
Vincentas Lamanauskas \\ Šiauliai University, Lithuania
}

It is obvious that scientific writing is a special and complex part of academic activity. Researchers not only organise and conduct the research but also have to describe and publish them (or to spread information in other ways). Basically, there exist two very close, however quite different processes: scientific research organisation and accomplishment and the accomplished scientific research description. For the first process, the most essential are the abilities to carry out the research (plan, design, conduct, analyse, systematize and so on), whilst for the second process, the most essential are special abilities (find and evaluate print and electronic resources suitable for the academic text and to present original arguments based on academic goal search, to critically think and use the appropriate information while writing articles and so on). It is understandable that such descriptions have to correspond to general requirements of such type of works both in respect of structure, presentation, and content. Qualitative scientific works are written and submitted in a scientific style, correct, clear and accurate English (or other) language.

One can think that scientific work structure despite of various specificities depending on science field/direction, consists of three main parts (introduction, subject/explanatory part, conclusions).

It is important to understand that scientific style manifests itself in certain stylistic features: abstractness, accuracy, objectivity, consistency. Writing a scientific article, one has to keep to a certain degree of structuring. This is an essential thing: it increases readability and comprehension. Let's discuss in brief the main structural parts of a scientific article. Abstract: the abstract should grip the reader. It should contain a lot of 'wow' in order that the reader wants to read further. Introduction: The introduction should contextualize the particular research and to answer the main question - what research has been conducted locally and globally to raise particular issue/idea/problem. It is a biography of the research problem. Research methodology: it should provide a summary of the procedures / instruments and materials/methods used. Also, researchers should explain the reasons why a particular method or procedure instead of others was applied. Research results: Results should be presented in detail and discussed accordingly without any mix with other studies. Discussion: it should present some comparisons, analyses and criticism and to answer the two main questions: What is already known about the particular issue/topic? What the current research adds to the body of knowledge? Conclusions: this part should focus on specifically answering the RQs.

Finally, the researchers have to understand that scientific articles are of various types and each of them performs its own mission (e.g., tutorial, observational, problematic, etc.). Important are the so-called preliminary conditions, i.e. cornerstone questions to which one should have an answer, e.g., What is the article preparation motivation? What publication is it prepared for? Who is the reader/auditorium? What is the current state of the research work? When one has to start preparing the article? Finally comes a generalising idea - you have to write not for yourself, but for others. One can dare to assert that you have to learn to write an article, and you can learn to write - only writing. 
Received 22 November 2019; Accepted 18 December 2019

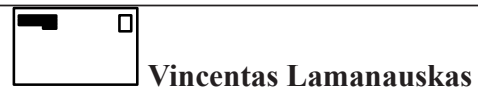

PhD., Professor, Senior Researcher, Research Institute, University of Šiauliai, 25-125 P. Višinskio Street, Šiauliai, Lithuania.

E-mail: vincentas.lamanauskas@su.lt

Website: https://www.researchgate.net/profile/Vincentas_Lamanauskas 